Research Article

\title{
Tooth Surface Modification for Helical Gear Pairs considering Mesh Misalignment Tolerance
}

\author{
Guosheng Han $\mathbb{D}^{1},{ }^{1}$ Bing Yuan $\mathbb{D}^{2},{ }^{2}$ and Guan Qiao $\mathbb{D}^{3}$ \\ ${ }^{1}$ School of Mechanical and Automotive Engineering, South China University of Technology, Guangzhou 510640, China \\ ${ }^{2}$ School of Mechanical Engineering, Xi'an Technological University, Xi'an 710021, China \\ ${ }^{3}$ Inner Mongolia Key Laboratory of Advanced Manufacturing Technology, Inner Mongolia University of Technology, \\ Huhhot 010051, China \\ Correspondence should be addressed to Guosheng Han; han.gs@mail.scut.edu.cn
}

Received 14 February 2021; Revised 17 March 2021; Accepted 23 March 2021; Published 22 April 2021

Academic Editor: F. Viadero

Copyright (c) 2021 Guosheng Han et al. This is an open access article distributed under the Creative Commons Attribution License, which permits unrestricted use, distribution, and reproduction in any medium, provided the original work is properly cited.

\begin{abstract}
Mesh misalignment in mating the gear tooth surface is common and difficult to be determined accurately because of system deformation and bearing clearances, as well as manufacturing and assembly errors. It is not appropriate to consider the mesh misalignment as a constant value or even completely ignore it in the tooth surface modification design. Aiming to minimize the expectation and variance of static transmission error (STE) fluctuations in consideration of mesh misalignment tolerance, a multiobjective optimization model of tooth surface modification parameters is proposed through coupling the NSGA-II algorithm and an efficient loaded tooth contact analysis (LTCA) model. The modified tooth flank of helical gear pairs is defined using 6 design variables which are related to profile modification, lead modification, and bias modification. The influences of mesh misalignment on time-dependent meshing stiffness (TDMS) and STE of unmodified and modified helical gear pairs are investigated. Then, the dynamic transmission error (DTE) of modified helical gears in consideration of mesh misalignment is discussed. The results indicate that the designed modified tooth surface shows good robustness to mesh misalignment.
\end{abstract}

\section{Introduction}

With the increase in requirement of low vibration of mechanical equipment, the reduction of the vibration level in the design and machining of a gear transmission device has always attracted widespread attention of researchers and engineers in recent years. Helical/double-helical gear pairs are widely used in marine, helicopter, mining, turbine, and other power transmission fields. Although the inborn higher contact ratio of helical gear pairs leads to lower vibration level of the system compared with spur gear systems, tooth surface modification is still usually used in the design of microparameters of helical/double-helical gear pairs in order to improve contact patterns and further reduce the vibration level of gear systems [1].

There are many research studies about parametric investigations, development of a new model, and the method of tooth surface modification for spur gears and helical gears, as well as double-helical gears. Wang et al. [2] proposed a slice model for calculating TDMS of a spur gear pair with lead crown and misalignment. Beinstingel et al. [3] developed an efficient algorithm for the calculation of TDMS of cylindrical gear pairs with profile modification. Vevit et al. [4] built an efficient tooth contact analysis model for spiral bevel gears with alignment errors. Fernández et al. [5-7] established a hybrid finite-element and analytical model for calculating TDMS of spur gear pairs and investigated the effect of profile deviations on mesh stiffness, transmission error, and power losses. Li [8] analyzed the tooth modification and mesh misalignment on the tooth engagement process of spur gears under a quasistatic contact condition. Miryam et al. [9] investigated the effects of profile modification on the load-sharing ratio and STE of spur gears. Ma et al. [10] and $\mathrm{Hu}$ et al. [11] studied the variation law of dynamic behaviors of a geared rotor system with the changes of profile modification parameters. Wang et al. [12] 
established a calculation method for determining the TDMS of a helical gear pair with gear errors. Peng et al. [13] developed an efficient model to predict the load distribution of helical gears under gear modification and mesh misalignment condition. Wang and Zhang [14] proposed an original closed-form determination approach of lead modification for cylindrical gear pairs. Bruyère and Velex $[15,16]$ developed the approximate closed-form expressions of profile modification using a perturbation method and gave two formulations to determine the optimal modification parameters for narrow-faced cylindrical gears. Maatar and Velex [17] developed a three-dimensional dynamic contact model of cylindrical gear systems with various gear modifications based on the length of contact lines and a contact algorithm. Wu et al. [18] determined profile modification amount of helical gears using static elastic deformation of gear teeth which is calculated by a static finite-element model and employed the dynamic contact finite-element model to investigate the influence of profile modification on vibration responses of the system. Taking a helical gear pair as an objective, Yuan et al. [19] determined the bias modification parameters based on a brute force optimization method and dynamic analysis of the system. Jiang and Fang [20] proposed a high-order transmission error modification method for spur and helical gear pairs. Wei et al. [21] studied the influence of tooth surface modifications on dynamic behaviors of the helical gear system by numerical calculation and experimental approaches. Ye and Tsai [22] developed an enhanced LTCA model in consideration of gear modification and the mesh misalignment caused by shaft deformation. Lagresle et al. [23] employed an adaptive multiobjective swarm algorithm to establish an optimization model of tooth surface modification for cylindrical gear pairs. Ma et al. [24] and Liu et al. [25] combined the design of tooth surface modification parameters and dynamic analysis aiming to obtain the optimal modification parameters. Jia et al. [26] proposed an iterative approach of dynamic deformation calculation of housing and determination of modification parameters for a multistage spur gear system. Aiming to minimize the relative velocity of mating gear teeth along the rotational direction, Wang [27] proposed an optimization model of three-dimensional modification parameters using a combination of tooth contact analysis, LTCA model, and system dynamics analysis. Benatar et al. [28] carried out the STE and DTE investigations of helical gear pairs with various tooth surface modification. Yuan et al. [29] proposed a novel tooth surface modification methodology for double-helical gear pairs considering system flexibility.

Besides, there are few research studies about the establishment of a robust optimization mathematical model of tooth surface modification parameters of gear pairs. To reduce system vibration and noise under multiple loads, Chan [30] used the response surface method to obtain the optimal tooth modification parameters of helical gears. Ghribi et al. [31] presented an original methodology to design robust profile modifications for cylindrical gears. Considering different weight distribution functions of applied torques, Artoni et al. [32] presented a novel gear modification approach for cylindrical gear pairs using the minimization of STE amplitude and peak contact stress as objective functions. Korta and Mundo [33,34] combined the finite-element method with the response surface method and obtained the robust solution of modification parameters by establishing and solving the response surface model of spur gear modification parameters.

In mating the tooth surface, mesh misalignment is an unavoidable problem because of system flexibility and spline and bearing clearance, as well as mounting and manufacturing errors [35]. It is almost impossible to be calculated and measured precisely in engineering practice. Mesh misalignment not only results in undesirable contact patterns but also further affects the vibration behaviors of the system. In fact, the contact state and vibration behaviors of modified helical gear pairs are influenced by the coupling effect between gear modification and uncertain mesh misalignment.

As mentioned above, most of the published work on gear modification focuses on the parametric investigation of gear modifications on the quasistatic and dynamic behaviors of spur or helical gears and design modified tooth surface without mesh misalignment or with constant mesh misalignment. There are few works about tooth surface modification design in consideration of load variation or mesh misalignment tolerance. The motivation of this study is to establish a multiobjective optimization mathematical model of tooth surface modification parameters for helical gear pairs in consideration of mesh misalignment tolerance and then to design a modified tooth surface with strong robustness to mesh misalignment for helical gear pairs. After this introduction, this paper is organized as follows: Section 2 establishes an efficient LTCA model of helical gear pairs with tooth modification and mesh misalignment, gives a comparison between the efficient LTCA model and the published model, and develops a multiobjective optimization model of combined gear modification for helical gear pairs in consideration of mesh misalignment tolerance. Section 3 establishes a dynamic model for helical gear pairs with tooth modification and mesh misalignment. Section 4 discusses the influence of mesh misalignment and combined tooth modification on mesh excitations and vibration responses of helical gear pairs and investigates the robustness of the designed tooth surface modification to mesh misalignment. Some conclusions are summarized in Section 5.

\section{Gear Modification Methodology of Helical Gear Pairs}

2.1. Gear Modification and Mesh Misalignment. There are three common tooth surface modification methods for helical gear pairs which include profile modification, lead modification, and bias modification. Profile modification is to modify the top and root of the tooth surface along the gear profile, which can significantly reduce the vibration of spur/ helical gear systems. Lead modification is to modify the tooth surface along gear width, which is usually used to improve the load distribution. Lead modification is an intentional helix deviation, and helix deviation has obvious contributions on the vibration level of helical gear systems; 
thus, the lead modification can also be used to reduce the system vibration. Bias modification is to modify the top and root of gear tooth along the normal direction of contact lines. The three types of tooth surface modification methods for helical gear pairs are shown in Figure 1. Profile modification, lead modification, and bias modification are combined to design the combined tooth surface modification in consideration of mesh misalignment tolerance.

The gear transmission system is a complex mechanical device with multiclearance and multicontact. Bearing clearance, manufacturing error, assembly error, and other various factors will cause gear mesh misalignment on mating gear tooth surfaces. These factors are not only inevitable but also difficult to measure precisely. The appearance of mesh misalignment will make the actual contact condition of mating tooth surfaces differ from the theoretical one. For the helical gear system, the actual contact condition of gear pairs not only affects the service life of the gear system but also seriously influences the vibration behaviors of the system. Various factors causing the mesh misalignment are summarized in the published work [35], and it is pointed out that the effect of mesh misalignment which is parallel to the plane of action (POA) has the most significant effect on tooth engagement of tooth surfaces. Its influence is equivalent to the helix deviation. Therefore, considering the mesh misalignment which is parallel to the plane of action, helix deviation is employed to establish the mesh misalignment model according to the published work [36], as shown in Figure 2.

2.2. Determination of TDMS and STE. An efficient LTCA model is established to determine the TDMS and STE of a helical gear pair with modification and mesh misalignment. Figure 3 shows the POA of a helical gear pair. $B_{1} B_{2} B_{3} B_{4}$ is the plane of action, $N_{1} N_{2}$ denotes the theoretical line of action, $r_{\mathrm{p}}$ and $r_{\mathrm{g}}$ are the base circle radii of the pinion and wheel, and $\omega_{\mathrm{p}}$ and $\omega_{\mathrm{g}}$ are the rotational directions of the two gears.

Under load condition, the pinion and wheel come into contact with each other, and then, the elastic deformation of mating gear tooth surfaces occurs. For a modified helical gear pair with mesh misalignment, the instantaneous contact model is shown in Figure 4. The deformation compatibility condition of each contact point pair is

$$
\delta_{i}+\varepsilon_{i}-\mathrm{STE}-d_{i}=0,
$$

where $\delta_{i}$ is the total deformation of contact point $i$, its value is equal to the summation of $\delta_{i 1}$ and $\delta_{i 2}, \varepsilon_{i}$ is the initial clearance of contact point $i$, STE is the rigid body approach of the two gears, which also refers to static transmission error, and $d_{i}$ is the residual clearance of contact point $i$.

For all contact point pairs at each meshing position, the matrix form of the deformation compatibility condition can be written as

$$
\boldsymbol{\delta}+\varepsilon-\mathrm{STE}-\mathbf{d}=0,
$$

where $\delta$ is the total deformation vector, $\varepsilon$ is the initial clearance vector before load, and $\mathbf{d}$ is the residual clearance vector after load.
The gear deformation consists of global deformation and local contact deformation. The global deformation increases linearly with the increased applied force, and the local contact deformation increases nonlinear with the increased applied force. Thus, the total deformation vector can be written as

$$
\boldsymbol{\delta}=\boldsymbol{\lambda}_{\text {Global }} \mathbf{F}+\mathbf{u}_{\text {Local }},
$$

where $\lambda_{\text {Global }}$ is the global deformation flexibility matrix of potential contact points, $\mathbf{F}$ is the force vector of potential contact points, $\mathbf{u}_{\text {Local }}$ is the local contact deformation vector.

The matrix form of the deformation compatibility condition at each meshing position can be written as

$$
\lambda_{\text {Global }} \mathbf{F}+\mathbf{u}_{\text {Local }}+\varepsilon-\mathrm{STE}-\mathbf{d}=0 .
$$

After load, when the load at the potential contact point is larger than zero, it means that the two mating tooth surfaces have come into contact at this potential contact point, and the residual clearance at this potential contact point is zero. When the load at the contact point is equal to zero, it means that the two tooth surfaces have not come into contact at this potential contact point and the residual clearance at this potential contact point is larger than zero. The judging condition can be written as

$$
\begin{cases}\text { When } F_{i}>0, & d_{i}=0, \\ \text { When } F_{i}=0, & d_{i}>0 .\end{cases}
$$

For each engagement position, the summation of the loads on all arranged contact points should be equal to the normal meshing force. It can be expressed as

$$
\sum_{i=1}^{n} F_{i}=\mathbf{I F}=P
$$

where $\mathbf{I}$ is an identity matrix with $n$ order.

\subsection{Global Deformation and Local Contact Deformation.} When the efficient LTCA model is established, it is very important and necessary to calculate the global deformation flexibility matrix of potential contact points on gear tooth surfaces. In the published works, finite-element substructure technology combined with a two-dimensional difference method is employed to calculate the global deformation flexibility matrix. This approach needs to establish threedimensional finite-element models of the pinion and wheel, respectively, and the calculation is time consuming. In this section, combing the potential energy method and thin slice method, the determination method of the global deformation flexibility matrix of potential contact points is proposed.

Both the pinion and wheel are discretized into a series of gear slices along gear width. The sliced gear model and geometric parameters of gear slices are shown in Figure 5. When the normal meshing force acts on the gear tooth surface, the deformation of the gear slice can be divided into bending deformation, shear deformation, axial compression deformation, gear body deformation, and local contact deformation [37]. The first four types of deformations 


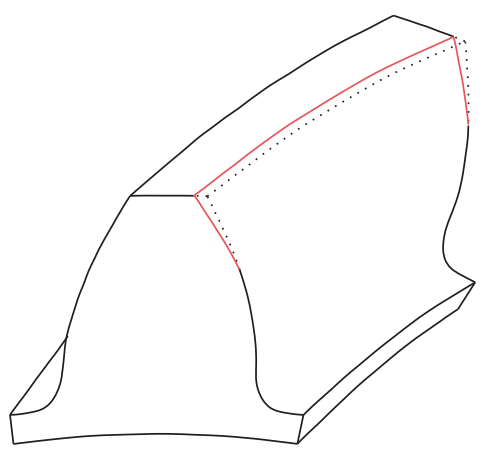

(a)

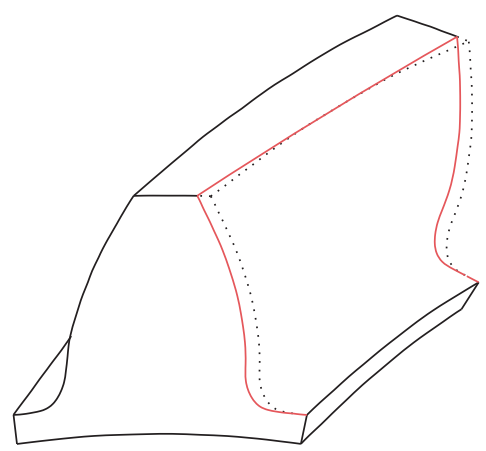

(b)

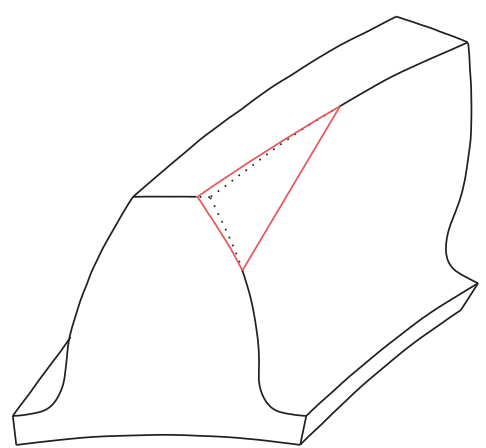

(c)

Figure 1: Three types of tooth surface modification methods for helical gear pairs.

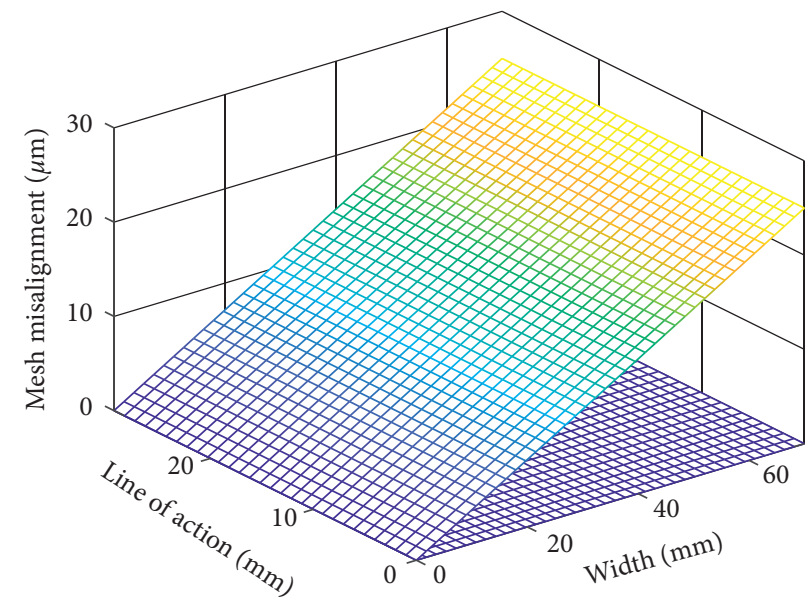

FIGURE 2: Mesh misalignment model for a helical gear pair.

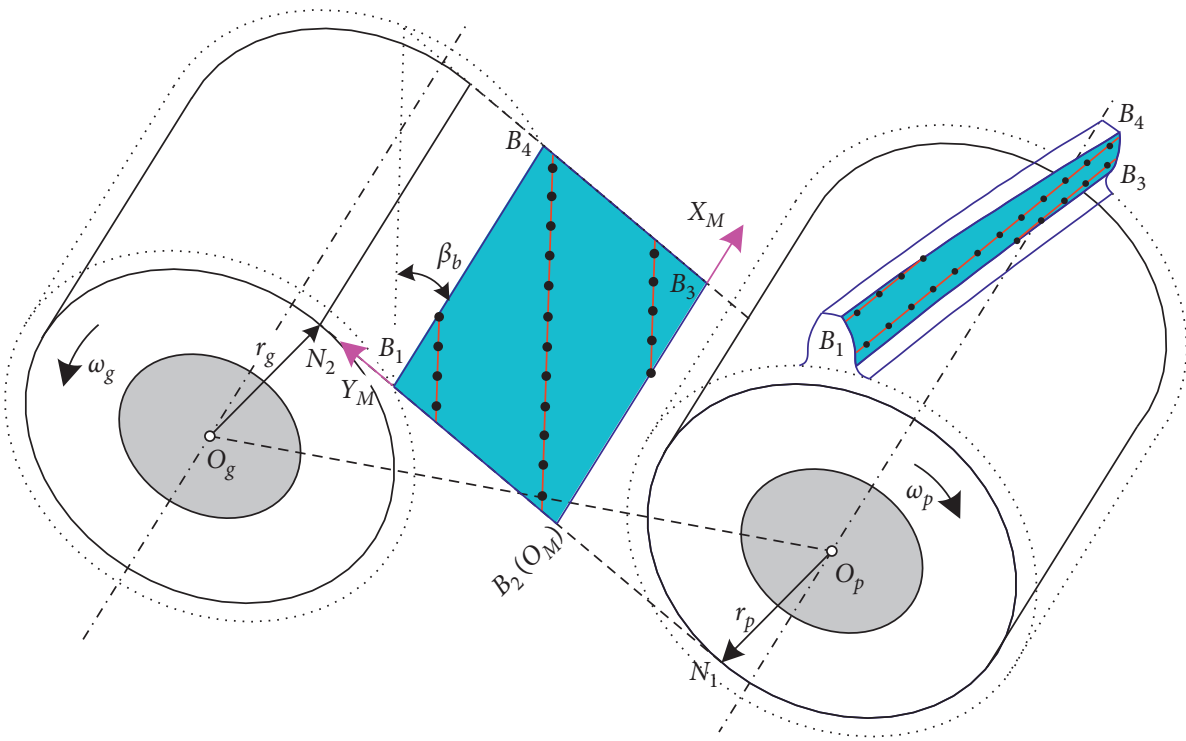

- Contact point

Contact line

Plane of action

Figure 3: POA of a helical gear pair. 


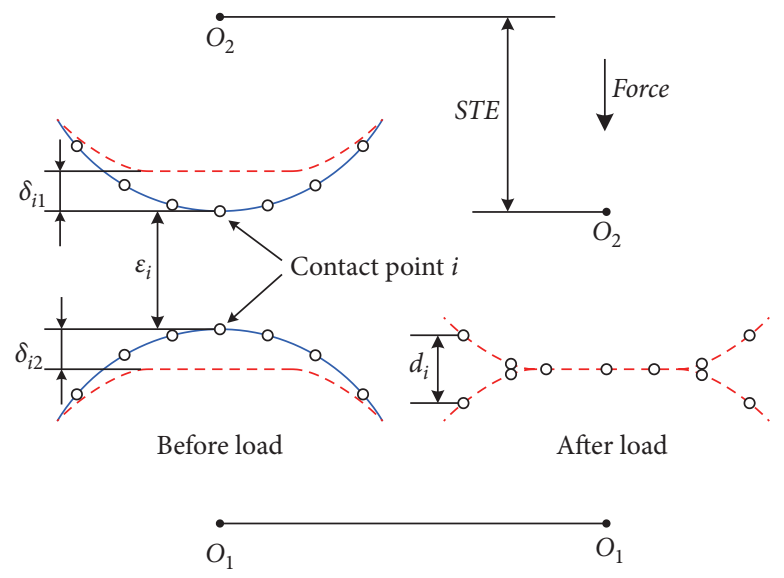

FIgURE 4: Instantaneous contact model for a modified helical gear pair with mesh misalignment.
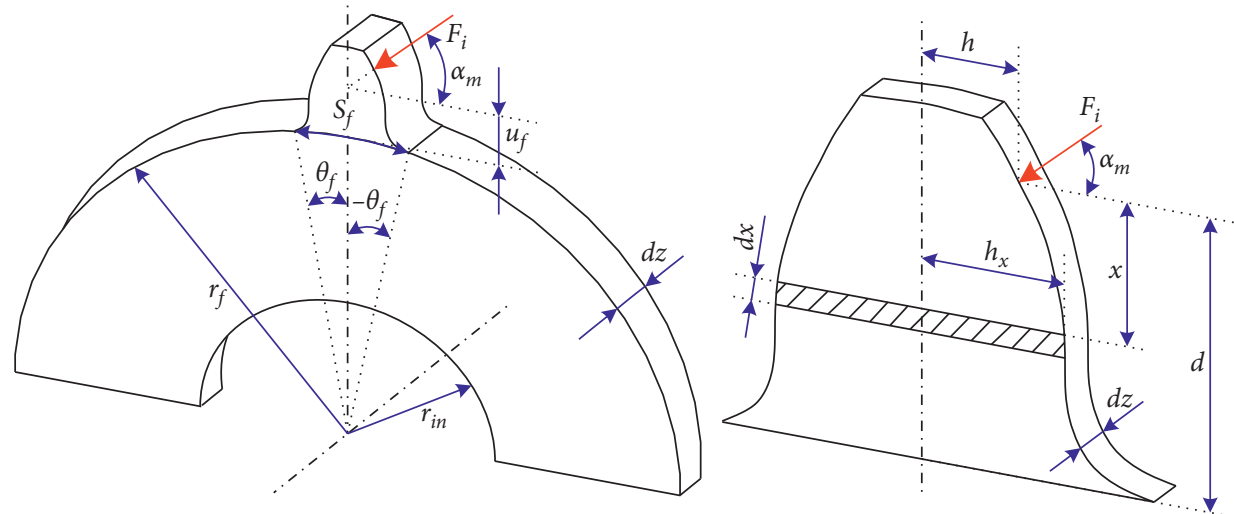

FIGURE 5: Sliced gear model and force analysis.

increase linearly with the increased normal meshing force, and the local contact deformation changes nonlinearly with the variation of normal meshing force [38].

The potential energy of bending deformation of the gear tooth under load can be determined using

$$
U_{b}=\frac{F^{2}}{2 K_{b}}=\int_{0}^{d} \frac{M^{2}}{2 \mathrm{EI}_{x}} \mathrm{~d} x .
$$

The potential energy of shear deformation of the gear tooth under load can be determined using

$$
U_{s}=\frac{F^{2}}{2 K_{s}}=\int_{0}^{d} \frac{1.2 F_{b}^{2}}{2 \mathrm{GA}_{x}} \mathrm{~d} x
$$

The potential energy of axial compression deformation of the gear tooth under load can be determined using

$$
U_{a}=\frac{F^{2}}{2 K_{a}}=\int_{0}^{d} \frac{F_{a}^{2}}{2 \mathrm{EA}_{x}} \mathrm{~d} x
$$

where $E$ and $G$ are Young's modulus and shear modulus of the gears and $A_{x}$ denotes the area moment of inertia and area of the section where the distance between the section and the acting point of the normal meshing force is $x$. The values of these parameters can be determined using

$$
G=\frac{E}{2(1+\nu)}, A_{x}=2 h_{x} \mathrm{~d} z, I_{x}=\frac{2}{3} h_{x}^{3} \mathrm{~d} z .
$$

$F_{b}, F_{a}$, and $M$ can be calculated using

$$
F_{b}=F \cos \alpha_{m}, F_{a}=F \sin \alpha_{m}, M=F_{b} x-F_{a} h .
$$

Substituting equation (11) into equation (7), the bending deformation flexibility of sliced gears can be determined using

$$
\lambda_{b}=\frac{1}{K_{b}}=\int_{0}^{d} \frac{\left(x \cos \alpha_{m}-h \sin \alpha_{m}\right)^{2}}{\mathrm{EI}_{x}} \mathrm{~d} x .
$$

Substituting equation (11) into equation (8), the shear deformation flexibility of sliced gears can be determined using

$$
\lambda_{s}=\frac{1}{K_{s}}=\int_{0}^{d} \frac{1.2 \cos ^{2} \alpha_{m}}{\mathrm{GA}_{x}} \mathrm{~d} x .
$$

Substituting equation (11) into equation (9), the axial compression deformation flexibility of sliced gears can be determined using 


$$
\lambda_{a}=\frac{1}{K_{a}}=\int_{0}^{d} \frac{\sin ^{2} \alpha_{m}}{\mathrm{EA}_{x}} \mathrm{~d} x .
$$

When the normal meshing force $F$ acts on one gear, the elastic deformation of gear body can be determined using [39]

$$
\xi_{f}=\frac{F \cos ^{2} \alpha_{m}}{E \mathrm{~d} z}\left\{L^{*}\left(\frac{u_{f}}{S_{f}}\right)^{2}+M^{*}\left(\frac{u_{f}}{S_{f}}\right)+P^{*}\left(1+Q^{*} \tan ^{2} \alpha_{m}\right)\right\},
$$

where $u_{f}$ and $S_{f}$ are shown in Figure 5. The coefficients $L^{*}$, $M^{*}, P^{*}$, and $Q^{*}$ can be determined using

$$
X_{i}^{*}\left(h_{f i}, \theta_{f}\right)=\frac{A_{i}}{\theta_{f}^{2}}+B_{i} h_{f i}^{2}+\frac{C_{i} h_{f i}}{\theta_{f}}+\frac{D_{i}}{\theta_{f}}+E_{i} h_{f i}+F_{i},
$$

where $X^{*}$ refers to $L^{*}, M^{*}, P^{*}$, and $Q^{*}$ and $h_{f i}=r_{f} / r_{\text {in }}$. The values of $A_{i}, B_{i}, C_{i}, D_{i}, E_{i}$, and $F_{i}$ can be found in the published work [39].

Hence, the deformation flexibility of gear body can be calculated using

$$
\lambda_{f}=\frac{1}{K_{f}}=\frac{\xi_{f}}{F}
$$

When the bending deformation flexibility, shear flexibility, and axial compression flexibility of the pinion and wheel are determined, the global deformation flexibility can be determined using

$$
\lambda_{\text {Global }}=\sum_{i=1}^{2}\left(\delta_{b i}+\delta_{s i}+\delta_{a i}+\delta_{f i}\right)
$$

where $i=1,2$ denotes to pinion and wheel.

The local contact deformation of each contact point can be determined using [40]

$$
u_{\text {Local }}=\frac{4 F_{i}}{\mathrm{~d} z} \frac{1-v^{2}}{\pi E}\left[\ln \frac{2 \sqrt{k_{1} k_{2}}}{a}-\frac{v}{2(1-v)}\right],
$$

where $F_{i}$ is the normal force acting on the potential contact point $i, \mathrm{~d} z$ is length of equivalent contact line of arranged contact point $i$, and $k_{1}$ and $k_{2}$ are shown in Figure 6. $a$ is the half width of contact along the normal direction of contact line, and it can be calculated by

$$
a=\sqrt{\frac{8 F / b \rho_{1} \rho_{2}}{\left(\rho_{1}+\rho_{2}\right)\left(1-v^{2}\right) / \pi E}}
$$

where $E$ and $v$ are the elastic modulus and Poisson's ratio of the material and $\rho_{1}$ and $\rho_{2}$ are the curvature radii of the pinion and wheel.

2.4. Comparison between the Efficient LTCA Model and the Published Model. Taking a helical gear pair as an example, the mesh stiffness of the gear pair is calculated using the presented model in this section, and the obtained results are compared with those calculated using the ISO 6336 standard. Under different load conditions, the STE fluctuations

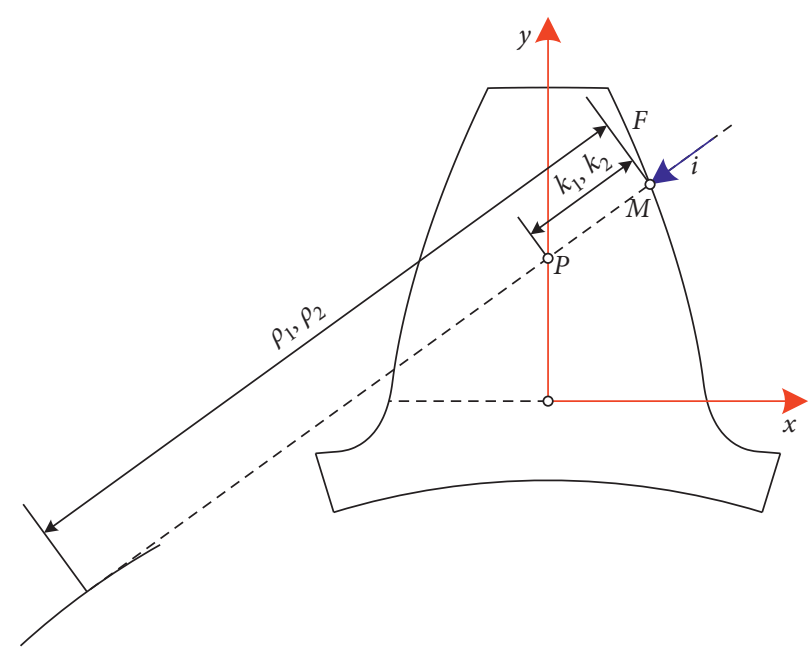

FIgURE 6: Geometric parameters for local contact deformation calculation.

of the gear pair with modifications obtained from different models are also compared. The basic parameters of the gear pair are given in Table 1 . When the helical gear pair is unmodified, the comparison of mesh stiffness obtained from different methods is shown in Table 2. It can be seen that the mean mesh stiffness value obtained from the proposed method agrees well with that obtained from the ISO 6336 standard.

When the tooth surface of the pinion is modified with a profile crown of $20 \mu \mathrm{m}$ and lead crown of $10 \mu \mathrm{m}$, the STE fluctuations of the modified helical gear pair under different normal meshing force conditions are shown in Figure 7. It can be seen that, with the increase of normal meshing force, the STE fluctuation of the modified helical gear pair shows a complex variation tendency of "decrease-increase-decreaselinearly increase." The numerical results obtained from the presented model agree well with those calculated using the published model [38]. Besides, it is unnecessary to establish the three-dimensional finite-element model of gear pairs; thus, the calculation efficiency of the normal flexibility matrix of arranged contact points on the gear tooth surface is greatly improved.

\subsection{Multiobjective Optimization Model of Combined Tooth} Surface Modification. Mesh misalignment is common and inevitable, and it is difficult to measure accurately; thus, it is not appropriate to consider the mesh misalignment as a constant value in the tooth surface modification design. The tolerance range of mesh misalignment should be considered. In order to make the combined tooth surface modification to have good robustness to mesh misalignment, two objective functions need to be defined. The first objective function is to minimize the expectation of STE fluctuations in the tolerance range of mesh misalignment, and the another objective function is to minimize the variance of STE fluctuations in the tolerance range of mesh misalignment. The multiobjective optimization model of combined tooth surface modification can be expressed as 
TABLE 1: Basic parameters of gears.

\begin{tabular}{lc}
\hline Parameter names & Values \\
\hline Tooth number & $29 / 61$ \\
Normal module $(\mathrm{mm})$ & 6 \\
Width $(\mathrm{mm})$ & 70 \\
Bottom clearance coefficient & 0.25 \\
Helix angle $\left(^{\circ}\right)$ & 20 \\
Pressure angle $\left({ }^{\circ}\right)$ & 20 \\
Addendum coefficient & 1 \\
\hline
\end{tabular}

TABle 2: Comparison of mesh stiffness obtained from different methods.

\begin{tabular}{lcc}
\hline Methods & $\begin{array}{c}\text { Mean mesh stiffness } \\
(\mathrm{N} /(\mathrm{mm} \cdot \mu \mathrm{m}))\end{array}$ & Difference \\
\hline ISO 6336 & 20.69 & - \\
Proposed method & 20.92 & $1.11 \%$ \\
\hline
\end{tabular}

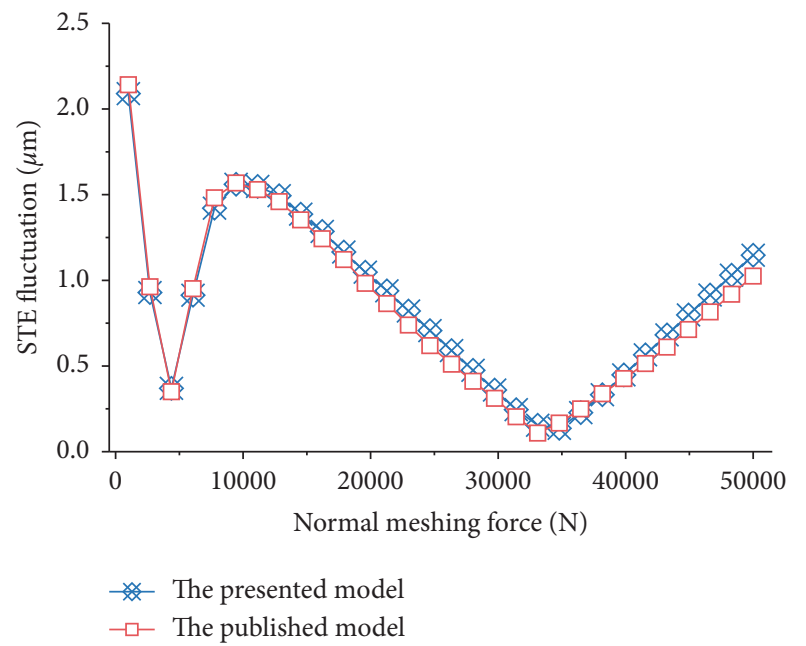

FIGURE 7: STE fluctuations of a modified helical gear pair under different load conditions.

$\min . F(x)=\left\{f_{1}\left(x_{1}, x_{2}, x_{3}, x_{4}, x_{5}, x_{6}\right), f_{2}\left(x_{1}, x_{2}, x_{3}, x_{4}, x_{5}, x_{6}\right)\right\}$,

where $f_{1}$ and $f_{2}$ refer to the expectation and variance of STE fluctuations, respectively, $x_{1}$ and $x_{2}$ are the amount of profile modification, $x_{3}$ and $x_{4}$ are the amount and length of lead modification, and $x_{5}$ and $x_{6}$ are the amount and length of bias modification.

A combination of the efficient LTCA model and NSGAII algorithm is constructed to solve the multiobjective optimization mathematical model. The detailed flow chart is shown in Figure 8. Firstly, gear parameters, normal meshing force, and mesh misalignment tolerance are introduced, and 6 design variables for the multiobjective optimization model are defined to determine the modified tooth surface. Secondly, the maximum number of generations is set to 200, and the initial population size is also equal to 200 . The initial population of combined

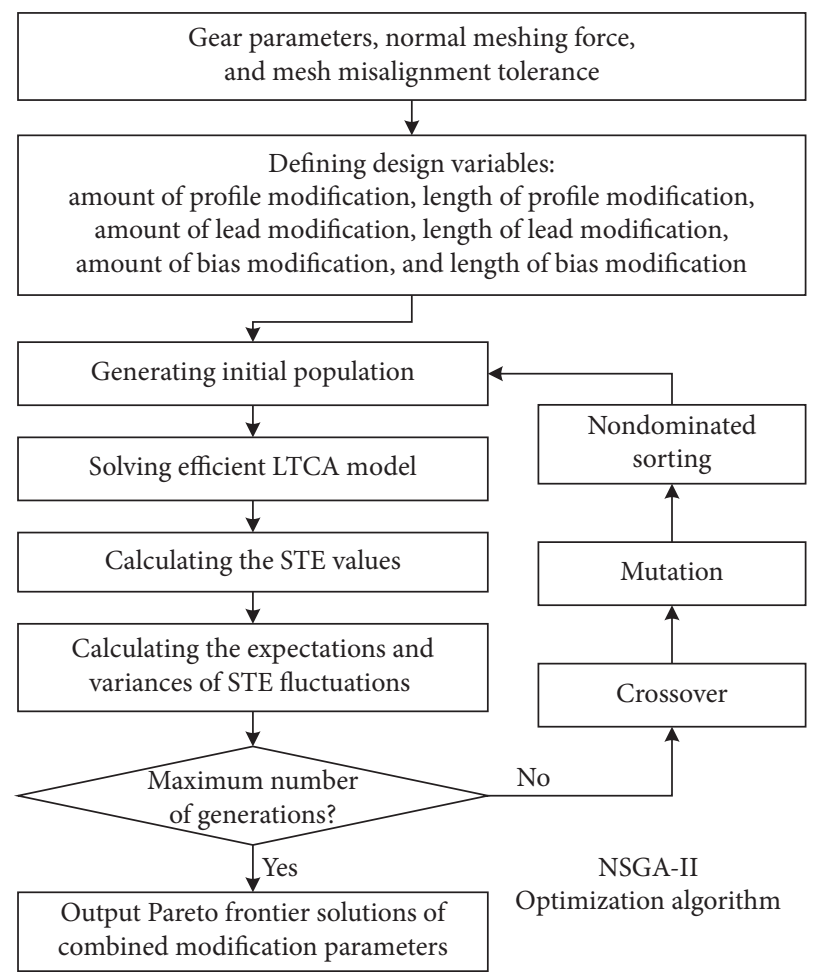

FIGURE 8: Multiobjective optimization model of combined tooth surface modification.

modification parameters is generated, and the expectation and variance of STE fluctuations of all the individuals are calculated fast using the efficient LTCA model in consideration of mesh misalignment tolerance. The offspring population can be obtained by selection, crossover, and mutation. Here, the Gaussian mutation operator is adopted. Then, the populations of the two generations are combined to perform fast nondominated sorting, and the suitable individuals are selected to form a new parent population. The procedure is repeated until the current number of generations reaches the maximum number. Finally, the Pareto frontier solutions of combined modification parameters are output.

\section{Dynamic Model of a Helical Gear Pair with Tooth Surface Modification and Mesh Misalignment}

Considering 3 translational and 1 rotational degrees of freedom for each gear, the dynamic model of a helical gear pair is established using a lumped parameter method, as shown in Figure 9. $O_{p}$ and $O_{g}$ are the rotational centers of the pinion and wheel, and $r_{p}$ and $r_{g}$ are the base circles of the two gears. $\beta_{b}$ is the helix angle of base circle, $\alpha_{t}$ is the transverse pressure angle, $\psi$ is the phase angle of installation, and $T_{p}$ and $T_{g}$ are the input and output torques.

The generalized coordinate vector of a helical gear pair can be defined as

$$
\mathbf{q}=\left\{x_{p}, y_{p}, z_{p}, \theta_{z p}, x_{g}, y_{g}, z_{g}, \theta_{z g}\right\}^{T} .
$$




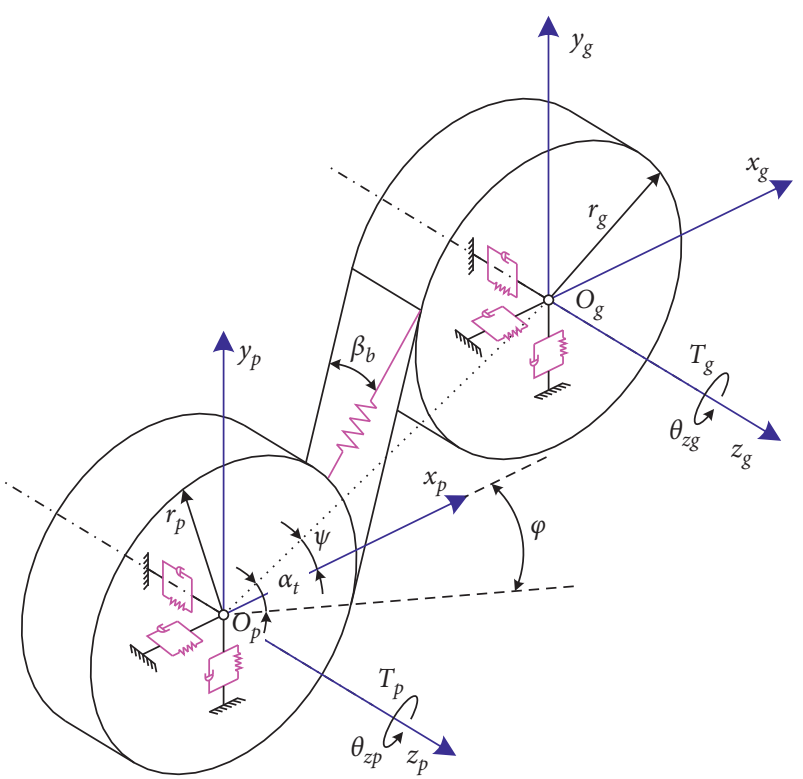

FIgURe 9: Dynamic model of a helical gear pair.

The relative displacement of the mating gear teeth along the normal line of action can be calculated using

$$
\tau=\mathbf{V q},
$$

where

$$
\begin{aligned}
\mathbf{V}= & {\left[\cos \beta_{b} \sin \varphi, \cos \beta_{b} \cos \varphi, \sin \beta_{b}, r_{p} \cos \beta_{b},\right.} \\
& \left.-\cos \beta_{b} \sin \varphi,-\cos \beta_{b} \cos \varphi,-\sin \beta_{b}, r_{g} \cos \beta_{b}\right] .
\end{aligned}
$$

The motion equations for a helical gear pair can be written as

$$
\left\{\begin{array}{l}
m_{p} \ddot{x}_{p}+\left\{c_{m} \tau+k_{m}(t)\left[\tau-e_{m}(t)\right]\right\} \cos \beta_{b} \sin \varphi=0, \\
m_{p} \ddot{y}_{p}+\left\{c_{m} \tau+k_{m}(t)\left[\tau-e_{m}(t)\right]\right\} \cos \beta_{b} \cos \varphi=0, \\
m_{p} \ddot{z}_{p}+\left\{c_{m} \tau+k_{m}(t)\left[\tau-e_{m}(t)\right]\right\} \sin \beta_{b}=0, \\
I_{z p} \ddot{\theta}_{z p}+\left\{c_{m} \tau+k_{m}(t)\left[\tau-e_{m}(t)\right]\right\} r_{p} \cos \beta_{b}=T_{p}, \\
m_{g} \ddot{x}_{g}-\left\{c_{m} \tau+k_{m}(t)\left[\tau-e_{m}(t)\right]\right\} \cos \beta_{b} \sin \varphi=0, \\
m_{g} \ddot{y}_{g}-\left\{c_{m} \tau+k_{m}(t)\left[\tau-e_{m}(t)\right]\right\} \cos \beta_{b} \cos \varphi=0, \\
m_{g} \ddot{z}_{g}-\left\{c_{m} \tau+k_{m}(t)\left[\tau-e_{m}(t)\right]\right\} \sin \beta_{b}=0, \\
I_{z g} \ddot{\theta}_{z g}+\left\{c_{m} \tau+k_{m}(t)\left[\tau-e_{m}(t)\right]\right\} r_{g} \cos \beta_{b}=T_{g},
\end{array}\right.
$$

where $m_{i}(i=p, g)$ and $I_{i}(i=p, g)$ are the mass and inertial of gears, $c_{m}$ is mesh damping, and $k_{m}(t)$ and $e_{m}(t)$ are TVMS and composite mesh error in consideration of tooth surface modification and mesh misalignment.

Considering the gear mesh excitations, the matrix form of the motion equations for a helical gear pair can be written as

$$
\mathbf{M} \ddot{q}(t)+\mathbf{C} \dot{\mathbf{q}}(t)+\mathbf{K}(t)[\mathbf{q}(t)-\mathbf{e}(t)]=\mathbf{F},
$$

where $\mathbf{M}$ and $\mathbf{C}$ are the mass matrix and damping matrix of the system, $\mathbf{F}$ is the external force vector, and $\mathbf{K}(t)$ and $\mathbf{e}(t)$ are the TVMS and composite mesh error considering gear modification and mesh misalignment.

\section{Results and Discussion}

In this section, the variation of TDMS and STE of the unmodified helical gear pairs under different mesh misalignment conditions is investigated at first. Then, a similar investigation for the modified helical gear pairs is conducted. Finally, in order to show the robustness of the vibration level of modified helical gear pairs to mesh misalignment, the DTE and DBF of modified helical gear pairs at various mesh misalignment conditions are discussed.

4.1. TDMS and STE of Unmodified Gear Pairs with Mesh Misalignment. When the mesh misalignment is $25 \mu \mathrm{m}$, the TDMS and STE curves under different normal meshing force conditions are shown in Figures 10 and 11. It can be observed that the TDMS value of helical gear pairs increases with the increase of normal meshing force. When the load is relatively small, the curve shapes of TDMS change greatly. When the normal meshing force is larger than $25000 \mathrm{~N}$, the curve shapes of TDMS do not change anymore with the increase of normal meshing force. The TDMS values increase slightly because the local contact deformation is nonlinearly related to the normal meshing force. With the increase of normal meshing force, the STE fluctuation values increase gradually. The fluctuation values of STE decrease first and then increase with the increase of meshing force.

When the normal meshing force is $20000 \mathrm{~N}$, the TDMS, STE, and load distribution of the unmodified helical gear pair under different mesh misalignment conditions are given in Figures 12-14. It can be observed that the curve shapes of TDMS of helical gear pairs remain constant when mesh misalignment is relatively small, and only the values change slightly. This is because the contact patterns reach the full tooth surface, as shown in Figures 14(a) and 14(b). When the mesh misalignment is relatively large, with the increase in mesh misalignment, the TDMS values decrease obviously and the curve shapes change irregularly because of the appearance of partial contact loss, as shown in Figures 14(c) and $14(\mathrm{~d})$. With the increase in mesh misalignment, the STE values of helical gear pairs increase significantly, and the fluctuation values of STE also increase gradually.

4.2. Pareto Frontier Solutions and the Modified Tooth Surface. When the normal meshing force of the helical gear pair is $30000 \mathrm{~N}$ and the tolerance region of mesh misalignment is from $-50 \mu \mathrm{m}$ to $50 \mu \mathrm{m}$, the evolution process of obtained results for combined tooth surface modification parameters is shown in Figure 15. It can be observed that when the number of generation is larger than 100, the distribution of obtained solutions are very close to each other. The final Pareto frontier solutions and the selected solution of tooth surface modification parameters are given in Figure 15(d). For the selected modification parameters, the amount of profile modification is 


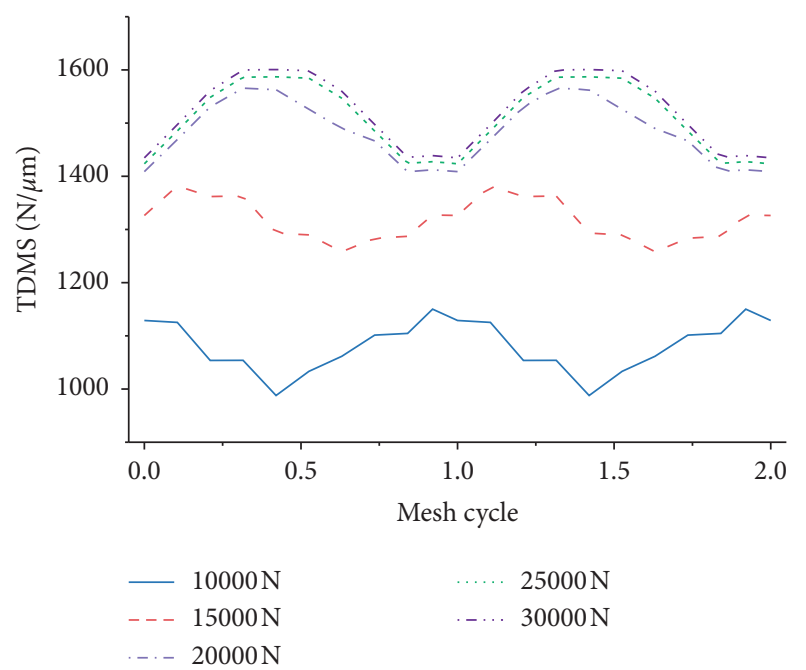

FIgURE 10: TDMS of the unmodified helical gear pairs under different load conditions.

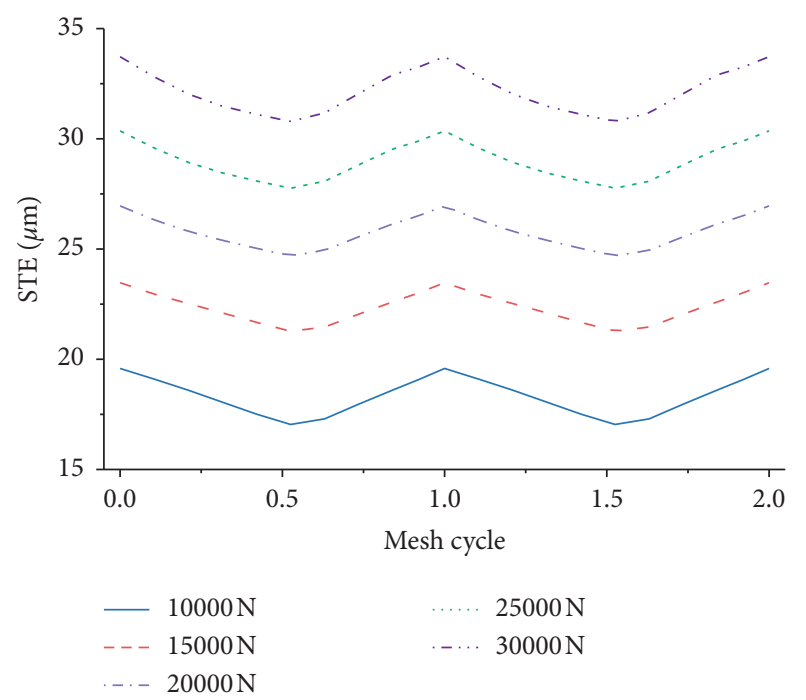

FIGURE 11: STE of unmodified helical gear pairs under different load conditions.

$100 \mu \mathrm{m}$, the length of profile modification is $7.7 \mathrm{~mm}$, the amount of lead modification is $57 \mu \mathrm{m}$, the length of lead modification is $15.4 \mathrm{~mm}$, the amount of bias modification is $68 \mu \mathrm{m}$, and the length of bias modification is $21.9 \mathrm{~mm}$. The corresponding expectation of STE fluctuations is $0.9411 \mu \mathrm{m}$, and the variation of STE fluctuations is $0.0135 \mu \mathrm{m}^{2}$.

4.3. TDMS and STE of Modified Gear Pairs with Mesh Misalignment. When the normal meshing force is $30000 \mathrm{~N}$, the TDMS curves of modified helical gear pairs under different mesh misalignment conditions are shown in Figure 16. It can be seen that the curve shapes of modified helical gear pairs are very different from the one of unmodified gears. For the combined tooth surface modification, the curve shape of TDMS changes to a certain extent

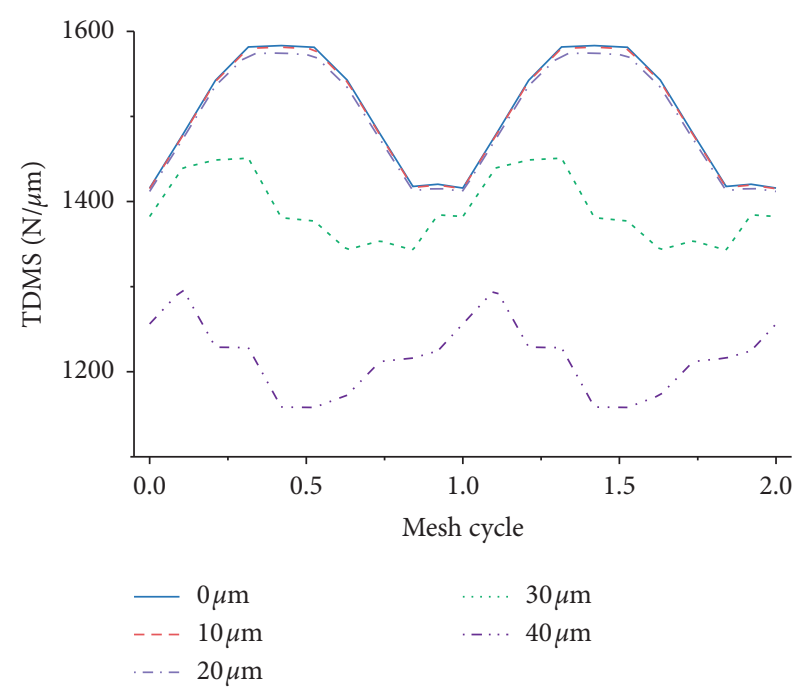

FIGURE 12: TDMS of the unmodified helical gear pairs under different mesh misalignment conditions.

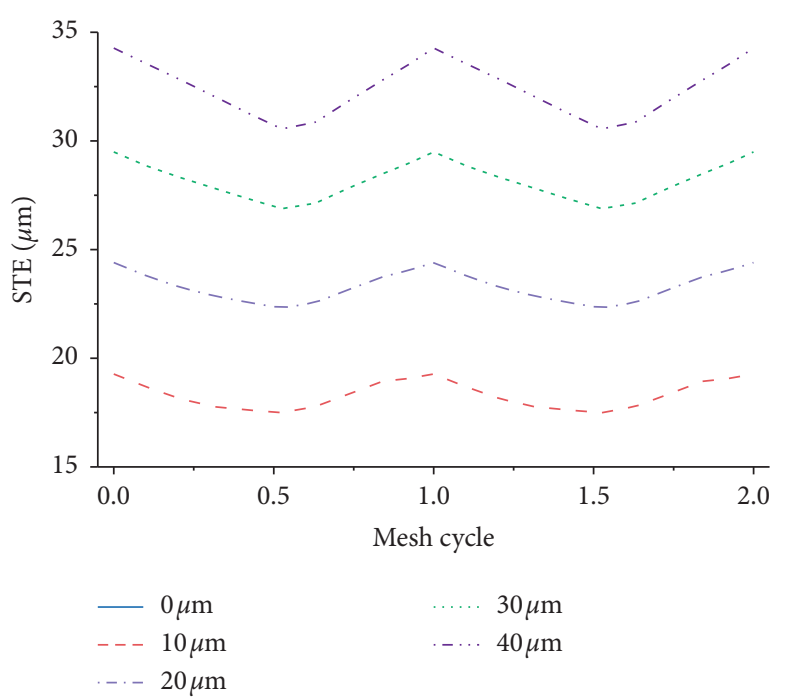

FIGURE 13: STE of unmodified helical gear pairs under different mesh misalignment conditions.

with the variation of mesh misalignment, but the mean value and peak-to peak values of TDMS change very little. When the mesh misalignment is relatively large, the mean value of TDMS tends to decrease slightly owing to the more serious partial contact loss.

When the mesh misalignment changes in the tolerance region, the comparison of STE fluctuations between modified helical gear pairs with the unmodified one is shown in Figure 17. It can be observed that the combined tooth surface modification not only reduces the STE fluctuation value of helical gear pairs under an ideal meshing condition but also reduces the STE fluctuation values significantly in the whole tolerance region of mesh misalignment. This means that the helical gear system can maintain a low vibration level when the meshing condition is within the tolerance range of mesh misalignment. 


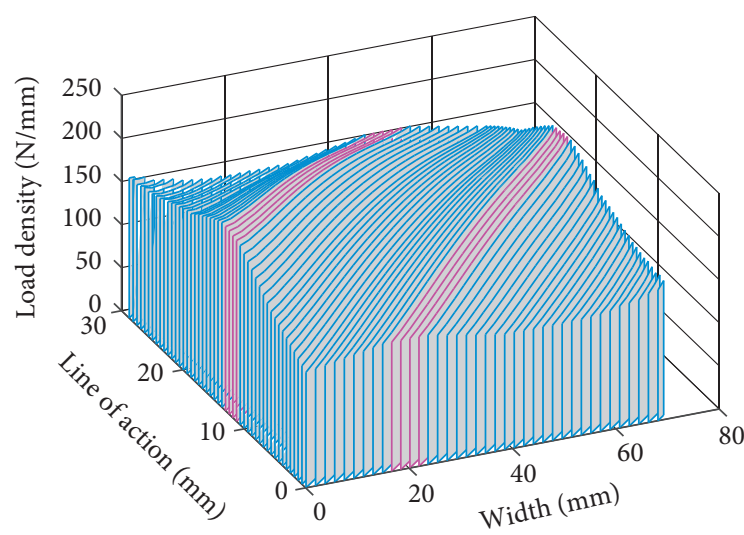

(a)

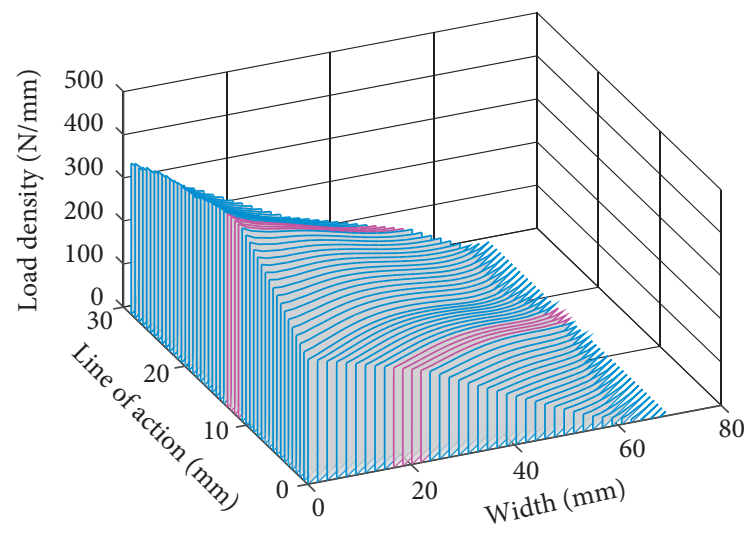

(c)

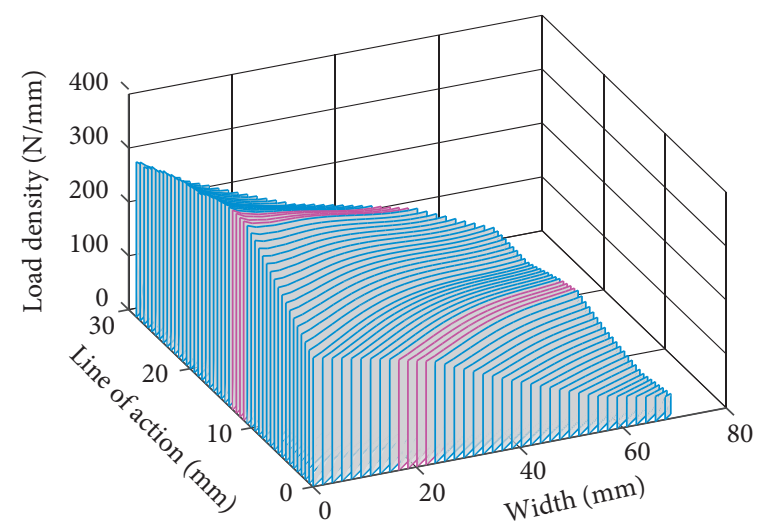

(b)

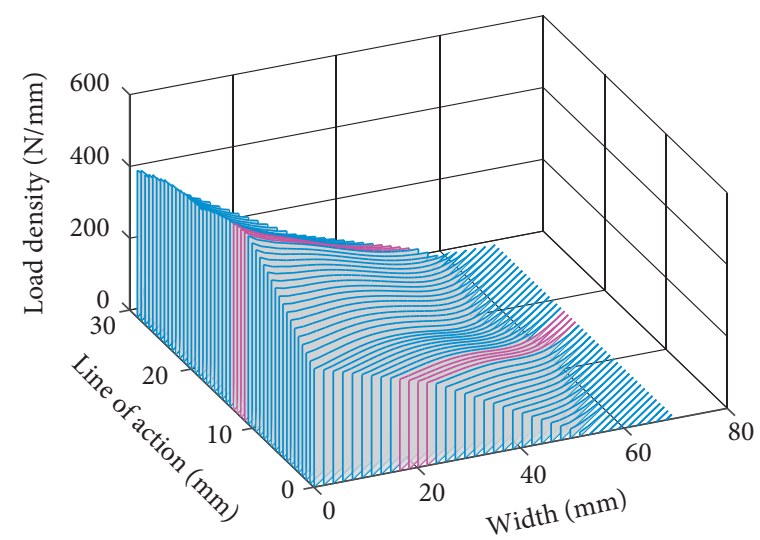

(d)

FiguRE 14: Load distribution of unmodified helical gear pairs under different mesh misalignment conditions. (a) $0 \mu \mathrm{m}$. (b) $20 \mu \mathrm{m}$. (c) $30 \mu \mathrm{m}$. (d) $40 \mu \mathrm{m}$.

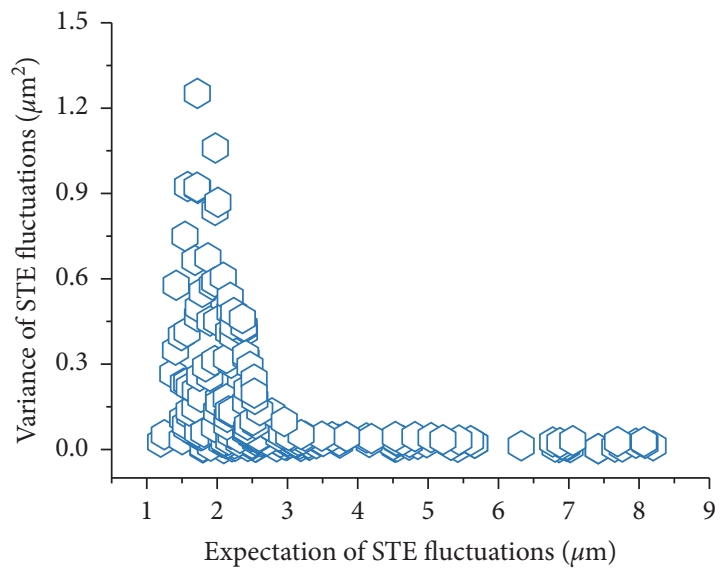

(a)

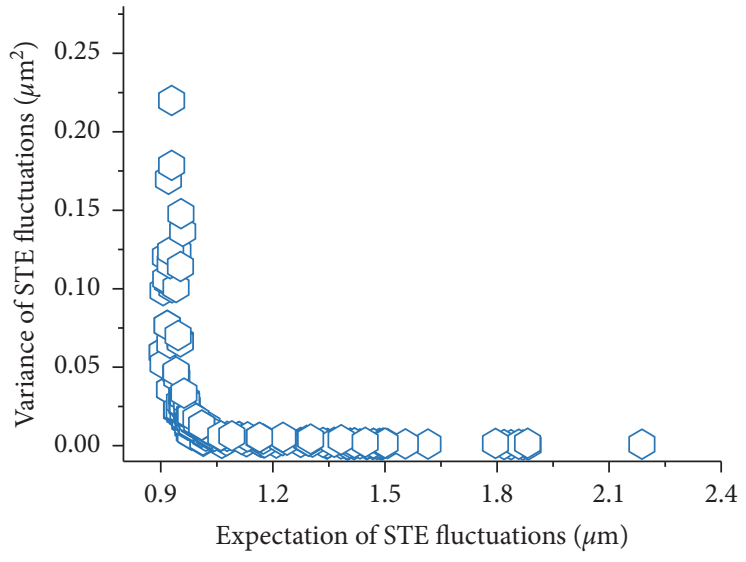

(b)

Figure 15: Continued. 


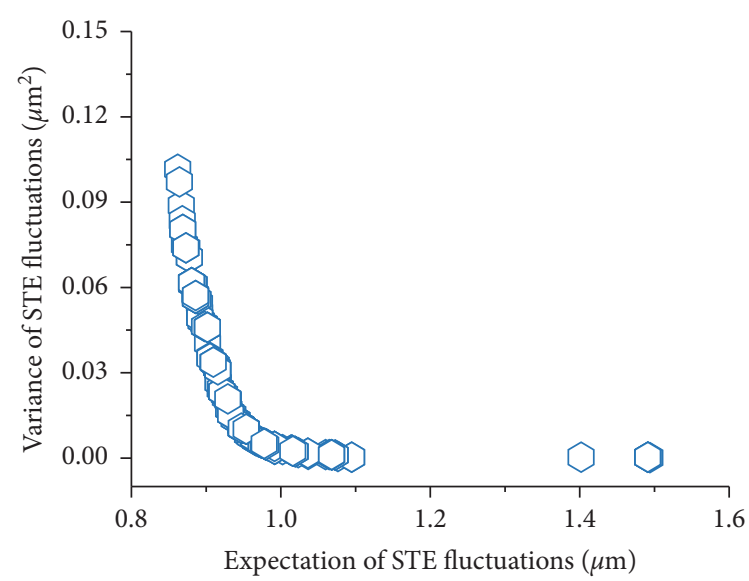

(c)

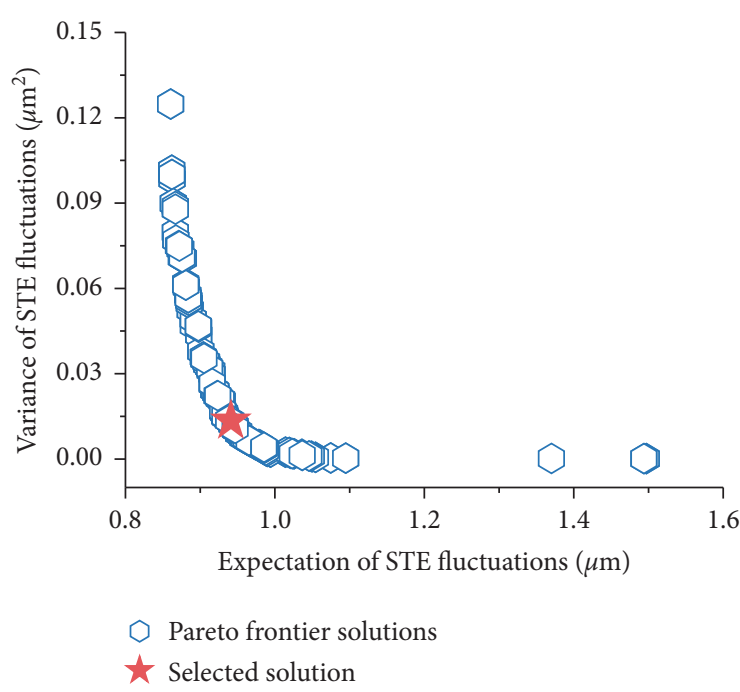

(d)

Figure 15: Evolution process of the obtained results for combined tooth surface modification parameters. (a) The 5th generation. (b) The 30th generation. (c) The 100th generation. (d) The 200th generation.

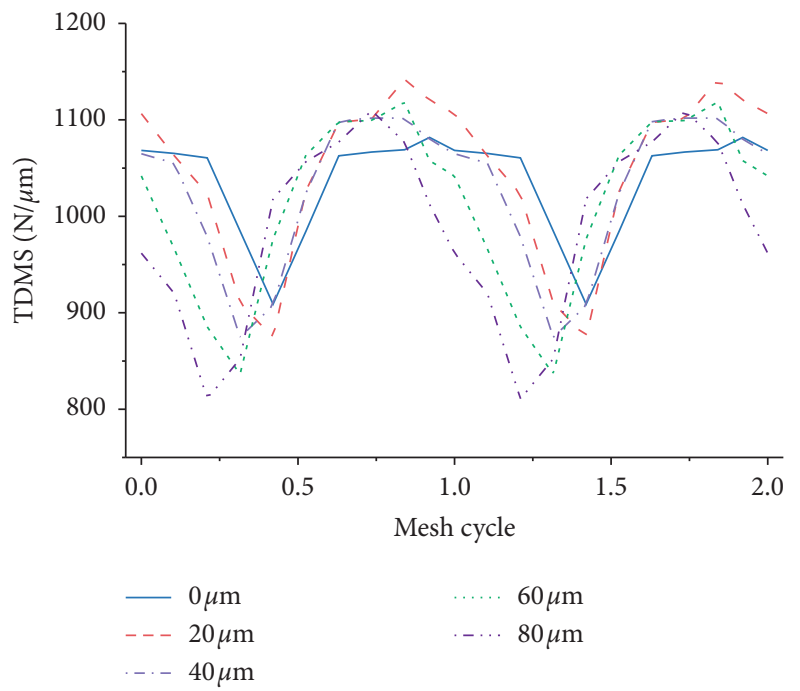

FIGURE 16: TDMS of modified helical gear pairs under different mesh misalignment conditions.

4.4. DTE of Modified Helical Gear Pairs with Mesh Misalignment. When the normal meshing force is $30000 \mathrm{~N}$, the root mean square (RMS) values of DTE of unmodified and modified helical gear pairs under different input speed conditions with the variation of the mesh misalignment condition are shown in Figure 18. It can be seen that the vibration of the unmodified helical gear system becomes large obviously with the increase in mesh misalignment. When the mesh misalignment is $80 \mu \mathrm{m}$, the resonance speed of the system is lower than that under other mesh misalignment conditions. This is because the phenomenon

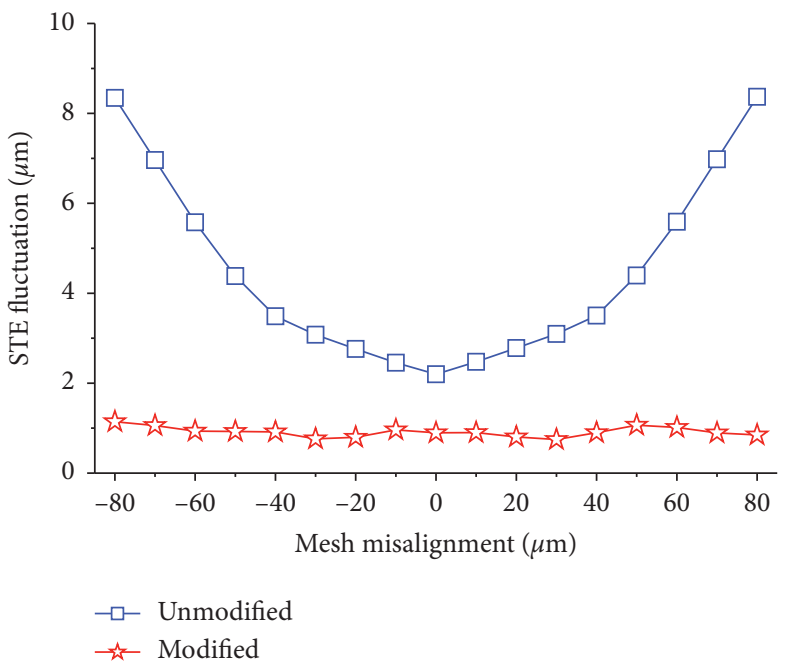

FIGURE 17: STE fluctuations of helical gear pairs under different mesh misalignment conditions.

of partial contact loss becomes more serious with the increase of mesh misalignment. In this situation, the introduced error excitations have much more contributions to the vibration level of the system. However, it can also be observed that the vibration level of the modified gear system is much weaker than that of the unmodified one. Also, with the changes of the mesh misalignment condition, the vibration level changes very little in most of the input speed conditions. It means that the designed tooth surface modification shows good robustness to mesh misalignment tolerance. 


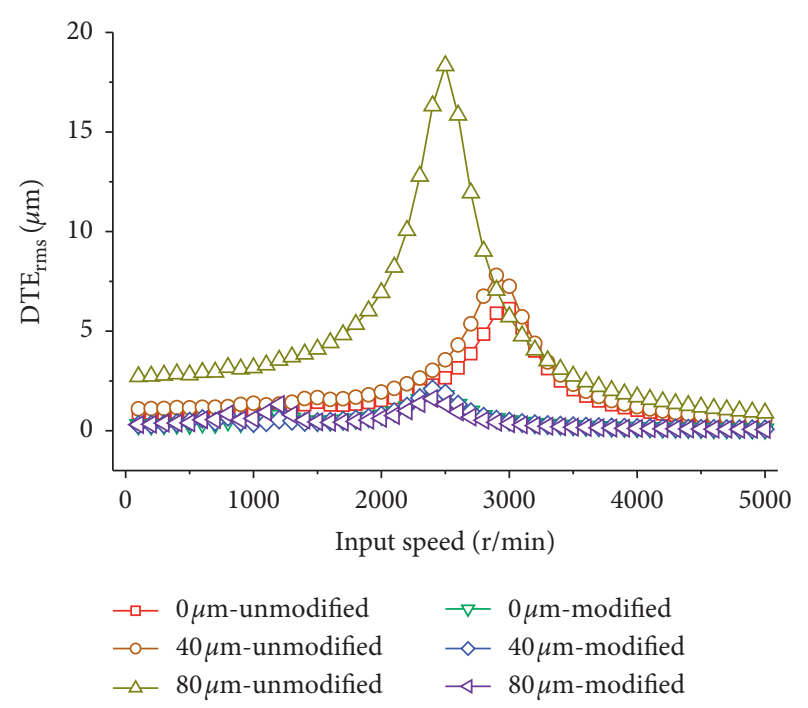

Figure 18: Root mean square values of DTE versus input speeds under different mesh misalignment conditions.

\section{Conclusions}

In this paper, three types of tooth surface modification methods are combined, and a multiobjective optimization mathematical model of tooth surface modification parameters is established in consideration of mesh misalignment tolerance. By constructing a combination of an efficient LTCA model and NSGA-II algorithm, the Pareto frontier solutions of modification parameters are obtained. Comprehensively considering mesh misalignment tolerance and designed tooth surface modification, the mesh excitations and vibration responses of the gear pair are investigated in detail. The main conclusions are summarized as follows:

(1) For a modified helical gear pair, the STE fluctuation values obtained from the presented model always agree well with those from the published model under different load conditions

(2) There is one solution of tooth surface modification parameters to make both the expectation and variance of STE fluctuations small when the mesh misalignment tolerance is considered

(3) When the mesh misalignment varies within a wide tolerance region, the designed tooth surface modification can make the helical gear system always work in low vibration level

\section{Data Availability}

The data used to support the findings of this study are included within the article.

\section{Conflicts of Interest}

The authors declare that there are no conflicts of interest regarding the publication of this paper.

\section{Acknowledgments}

This paper was supported by the National Natural Science Foundation of China (grant no. 52005382) and Natural Science Basic Research Program of Shaanxi (grant no. 2020JQ-807).

\section{References}

[1] D. Miler and M. Hoić, "Optimisation of cylindrical gear pairs: a review," Mechanism and Machine Theory, vol. 156, Article ID 104156, 2021.

[2] Q. Wang, K. Xu, T. Huai, H. Ma, and K. Wang, "A mesh stiffness method using slice coupling for spur gear pairs with misalignment and lead crown relief," Applied Mathematical Modelling, vol. 90, pp. 845-861, 2021.

[3] A. Beinstingel, M. Keller, M. Heider, B. Pinnekamp, and S. Marburg, "A hybrid analytical-numerical method based on Isogeometric Analysis for determination of time varying gear mesh stiffness," Mechanism and Machine Theory, vol. 160, Article ID 104291, 2021.

[4] M. Vivet, T. Tamarozzi, W. Desmet, and D. Mundo, "On the modelling of gear alignment errors in the tooth contact analysis of spiral bevel gears," Mechanism and Machine Theory, vol. 155, Article ID 104065, 2021.

[5] A. Fernandez, F. Viadero, M. Iglesias et al., "A model for the study of meshing stiffness in spur gear transmissions," Mechanism and Machine Theory, vol. 61, pp. 60-58, 2013.

[6] A. Fernandez, M. Iglesias, A. De-Juan et al., "Gear transmission dynamic: effects of tooth profile deviations and support flexibility," Applied Acoustics, vol. 77, pp. 137-149, 2014.

[7] A. Diez-Ibarbia, A. Fernandez-del-Rincon, A. De-Juan, M. Iglesias, P. Garcia, and F. Viadero, "Frictional power losses on spur gears with tip reliefs. The friction coefficient role," Mechanism and Machine Theory, vol. 121, pp. 15-27, 2018.

[8] S. Li, "Effects of misalignment error, tooth modifications and transmitted torque on tooth engagements of a pair of spur gears," Mechanism and Machine Theory, vol. 83, pp. 125-136, 2015.

[9] B. S. Miryam, M. Pleguezuelos, and I. P. José, "Influence of profile modifications on meshing stiffness, load sharing, and transmission error of involute spur gears," Mechanism and Machine Theory, vol. 139, pp. 506-525, 2019.

[10] H. Ma, J. Yang, R. Song, S. Zhang, and B. Wen, "Effects of tip relief on vibration responses of a geared rotor system," Proceedings of the Institution of Mechanical Engineers, Part C: Journal of Mechanical Engineering Science, vol. 228, no. 7, pp. 1132-1154, 2014.

[11] Z. Hu, J. Tang, J. Zhong, S. Chen, and H. Yan, "Effects of tooth profile modification on dynamic responses of a high speed gear-rotor-bearing system," Mechanical Systems and Signal Processing, vol. 76-77, pp. 294-318, 2016.

[12] Y. Peng, N. Zhao, P. Qiu, M. Zhang, W. Li, and R. Zhou, “An efficient model of load distribution for helical gears with modification and misalignment," Mechanism and Machine Theory, vol. 121, pp. 151-168, 2018.

[13] U. Weinberger, M. K. Otto, and K. Stahl, "Closed-form calculation of lead flank modification proposal for spur and helical gear stages," Journal of Mechanical Design, vol. 142, Article ID 031106, 2020.

[14] Q. Wang and Y. Zhang, "A model for analyzing stiffness and stress in a helical gear pair with tooth profile errors," Journal of Vibration and Control, vol. 23, no. 2, pp. 272-289, 2017. 
[15] J. Bruyère and P. Velex, "Derivation of optimum profile modifications in narrow-faced spur and helical gears using a perturbation method," Journal of Mechanical Design, vol. 135, no. 7, Article ID 071009, 2013.

[16] J. Bruyère, X. Gu, and P. Velex, "On the analytical definition of profile modifications minimising transmission error variations in narrow-faced spur helical gears," Mechanism and Machine Theory, vol. 92, pp. 257-272, 2015.

[17] M. Maatar and P. Velex, "Quasi-static and dynamic analysis of narrow-faced helical gears with profile and lead modifications," Journal of Mechanical Design, vol. 119, no. 4, pp. 474-480, 1997.

[18] Y.-j. Wu, J.-j. Wang, and Q.-k. Han, "Static/dynamic contact FEA and experimental study for tooth profile modification of helical gears," Journal of Mechanical Science and Technology, vol. 26, no. 5, pp. 1409-1417, 2012.

[19] B. Yuan, S. Chang, G. Liu et al., "Optimization of bias modification and dynamic behavior analysis of helical gear system," Advances in Mechanical Engineering, vol. 9, no. 11, pp. 1-14, 2017.

[20] J. Jiang and Z. Fang, "Design and analysis of modified cylindrical gears with a higher-order transmission error," Mechanism and Machine Theory, vol. 88, pp. 141-152, 2015.

[21] J. Wei, A. Zhang, G. Wang et al., "A study of nonlinear excitation modeling of helical gears with modification: theoretical analysis and experiments," Mechanism and Machine Theory, vol. 128, pp. 314-335, 2018.

[22] S.-Y. Ye and S.-J. Tsai, "A computerized method for loaded tooth contact analysis of high-contact-ratio spur gears with or without flank modification considering tip corner contact and shaft misalignment," Mechanism and Machine Theory, vol. 97, pp. 190-214, 2016.

[23] C. Lagresle, M. Guingand, J. P. D. Vaujany et al., "Optimization of tooth modifications for spur and helical gears using an adaptive multi-objective swarm algorithm," Proceedings of the Institution of Mechanical Engineers Part C: Journal of Mechanical Engineering Science, vol. 233, no. 21-22, pp. 7292-7308, 2019.

[24] H. Ma, X. Pang, R. Feng, and B. Wen, "Evaluation of optimum profile modification curves of profile shifted spur gears based on vibration responses," Mechanical Systems and Signal Processing, vol. 70-71, pp. 1131-1149, 2016.

[25] H. Liu, C. Zhang, C. L. Xiang, and C. Wang, "Tooth profile modification based on lateral- torsional-rocking coupled nonlinear dynamic model of gear system," Mechanism and Machine Theory, vol. 105, pp. 606-619, 2016.

[26] H. Jia, D. Qin, and C. Liu, "Novel tooth modification methodology for multistage spur gears considering dynamic deformation of housing," Proceedings of the Institution of Mechanical Engineers Part C: Journal of Mechanical Engineering Science, vol. 233, no. 21-22, pp. 7257-7269, 2019.

[27] C. Wang, "Study on 3-D modification for reducing vibration of helical gear based on TCA technology, LTCA technology and system dynamics," Mechanical Systems and Signal Processing, vol. 146, Article ID 106991, 2021.

[28] M. Benatar, M. Handschuh, and A. Kahraman, "Static and dynamic transmission error measurements of helical gear pair with various tooth modification," Journal of Mechanical Design, vol. 141, Article ID 103301, 2019.

[29] B. Yuan, G. Liu, Y. Yue, L. Liu, and Y. Shen, "A novel tooth surface modification methodology for wide-faced doublehelical gear pairs," Mechanism and Machine Theory, vol. 160, Article ID 104299, 2021.
[30] I. L. P. Chan, "Multi-objective optimization of the tooth surface in helical gears using design of experiment and the response surface method," Journal of Mechanical Science and Technology, vol. 24, no. 3, pp. 823-829, 2010.

[31] D. Ghribi, J. Bruyère, P. Velex et al., "A contribution to the design of robust profile modifications in spur and helical gears by combining analytical results and numerical simulations," Journal of Mechanical Design, vol. 134, no. 6, Article ID 061011, 2012.

[32] A. Artoni, M. Guiggiani, A. Kahraman et al., "Robust optimization of cylindrical gear tooth surface modifications within ranges of torque and misalignments," Journal of Mechanical Design, vol. 135, no. 12, Article ID 121005, 2013.

[33] J. A. Korta and D. Mundo, "Multi-objective micro-geometry optimization of gear tooth supported by response surface methodology," Mechanism and Machine Theory, vol. 109, pp. $278-295,2017$.

[34] J. A. Korta and D. Mundo, "A population-based meta-heuristic approach for robust micro-geometry optimization of tooth profile in spur gears considering manufacturing uncertainties," Meccanica, vol. 53, pp. 447-464, 2018.

[35] D. R. Houser, J. Harianto, and D. Talbot, "Gear mesh misalignment," Gear Solutions, vol. 6, pp. 34-43, 2006.

[36] J. Börner, M. Maier, and F. J. Joachim, "Design of transmission gearings for low noise emission-loaded tooth contact analysis with automated parameter variation," International Conference on Gears, Garching, 7-9 October 2013.

[37] Z. Chen and Y. Shao, "Dynamic simulation of spur gear with tooth root crack propagating along tooth width and crack depth," Engineering Failure Analysis, vol. 18, no. 8, pp. 2149-2164, 2011.

[38] L. Chang, G. Liu, and L. Wu, "A robust model for determining the mesh stiffness of cylindrical gears," Mechanism and Machine Theory, vol. 87, pp. 93-114, 2015.

[39] P. Sainsot, P. Velex, and O. Duverger, "Contribution of gear body to tooth deflections-a new bidimensional analytical formula," Journal of Mechanical Design, vol. 126, no. 4, pp. 748-752, 2004.

[40] P. Sainsot and P. Velex, "On contact deflection and stiffness in spur and helical gears," Mechanism and Machine Theory, vol. 154, Article ID 104049, 2020. 